Алиев И. С.

Таган Л. В.

Самоглядов А. Д.

Махмудов К. Д.

\title{
КОМБИНИРОВАННОЕ ОБРАТНО-ПРЯМОЕ ВЫДАВЛИВАНИЕ ПОЛЫХ КОНИЧЕСКИХ ДЕТАЛЕЙ
}

В производстве современных машин, приборов и изделий специального назначения полые конические детали получили широкое распространение. Для изготовления тонкостенных конических деталей традиционно используют различные способы листовой штамповки $[1,2]$. Одним из методов производства этих изделий является также технология точной объемной штамповки, позволяющая получить качественную деталь с высокой точностью размеров. Анализ способов объемной штамповки конических деталей позволил установить, что данный тип деталей целесообразно изготавливать способами холодного и горячего выдавливания, такими как обратное или прямое выдавливание, прямое выдавливание с раздачей и комбинированное обратно-прямое выдавливание [3].

При листовой штамповке, в зависимости от соотношения высоты тонкостенной конусной детали $h$ до наружного диаметра $d$ и величины угла образующей конуса $\alpha$, такие изделия разделяют на три группы - низкие, средние и высокие [2]. Наибольшую сложность в изготовлении штамповкой из листовой заготовки методом вытяжки имеют высокие конусные детали, для которых $h / d=0,8$ и $\alpha=10^{\circ}-30^{\circ}$. Применяют многопереходную вытяжку, которая включает 4-7 переходов [4]. Применение операций вытяжки полого полуфабриката и последующего обжима позволяет уменьшить количество переходов изготовления конусных изделий [5]. Преимуществами такого подхода является получение изделий с практически одинаковой толщиной стенки по высоте, так как при вытяжке имеет место утончение стенки придонной части полого полуфабриката, а при обжиме происходит утолщение этой части [5].

Обратное выдавливание (рис. 1, а) является наиболее энергоемким процессом [6], что обусловлено интенсивным однонаправленным течением металла в условиях всестороннего сжатия и значительного трения. При этом устойчивость заготовки недостаточна, что приводит к появлению разностенности деталей. Прямое выдавливание с раздачей конических деталей (рис. 1, б) ввиду разноименной схемы напряженного состояния требует меньших сил деформирования [7]. По этой причине и деформируемость заготовок может быть низкой, так как на кромке детали действуют окружные растягивающие напряжения.

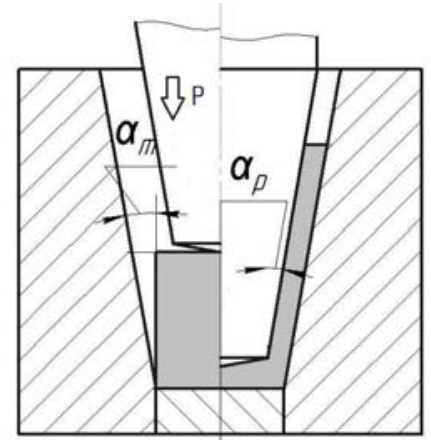

a

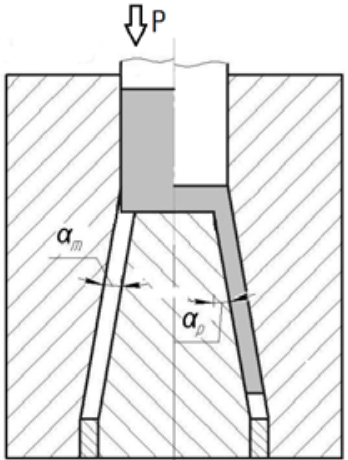

6

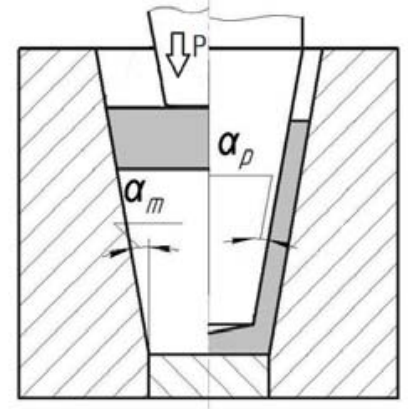

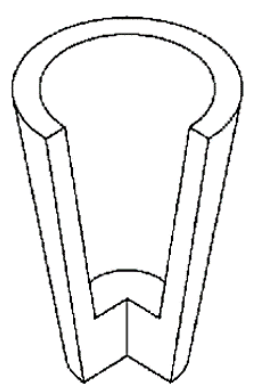

$\Gamma$

Рис. 1. Схемы выдавливания (а, б, в) полых деталей типа «конический стакан» (г) 
Перспективным методом штамповки конических деталей может быть комбинированное обратно-прямое выдавливание, позволяющие заметно снизить энергосиловые затраты на процесс деформирования, достичь наиболее точных размеров и улучшить качество получаемых изделий $[3,8]$. Для данной схемы характерно использование исходной фасонированной заготовки, размещаемой в верхней части полости матрицы (рис. 1, в). Основными параметрами, влияющими в данном процессе, являются углы наклона образующих матрицы и пуансона, условия контактного трения, а также форма и размеры заготовки, определяющие ее исходное положение в полости матрицы $[3,6,8]$. Наличие стадии обратного выдавливания является ограничивающим фактором для процесса комбинированного обратно-прямого выдавливания полых деталей. Для полной реализации преимуществ комбинированного способа и снижения протяженности стадии обратного выдавливания необходимо оценить возможности управления процессом формообразования деталей путем воздействия основными технологическими параметрами.

Целью работы является определение возможности реализации процесса комбинированного обратно-прямого выдавливания без стадии обратного выдавливания с выявлением количественных значений основных технологических параметров процесса.

Для теоретического анализа поставленной задачи использован метод конечных элементов, который реализован в программном комплексе QForm 2D [9]. Граничные условия для конечно-элементного анализа: материал заготовки - АД1; модуль Юнга - 69000 МПа; коэффициент Пуассона - 0,34; начальная температура заготовки $-20^{\circ} \mathrm{C}$. Размеры заготовки: больший диаметр конической заготовки $d_{1}=56$ мм; высота заготовки $h_{1}=30$ мм; угол наклона конуса $\alpha=10^{\circ}$. Размеры полученной детали: толщина дна $h_{2}=17$ мм; толщина стенки $s=$ 7 мм; общая высота детали $H=73$ мм;

Для описания поведения заготовки в процессе деформирования используется вязкопластическая среда. Условия контактного трения заданы по закону Зибеля. В качестве основных управляющих параметров были приняты коэффициенты трения на матрице и пуансоне, впоследствии варьировали и высоту размещения исходной заготовки в полости матрицы. За базовый вариант технологического процесса принят вариант с расположением заготовки в верхней части матрицы (см. рис. 1, в) и коэффициенты трения на поверхностях матрицы и пуансона, равные $\mu_{s}=\mu_{n}=0,08$ (рис. 2).

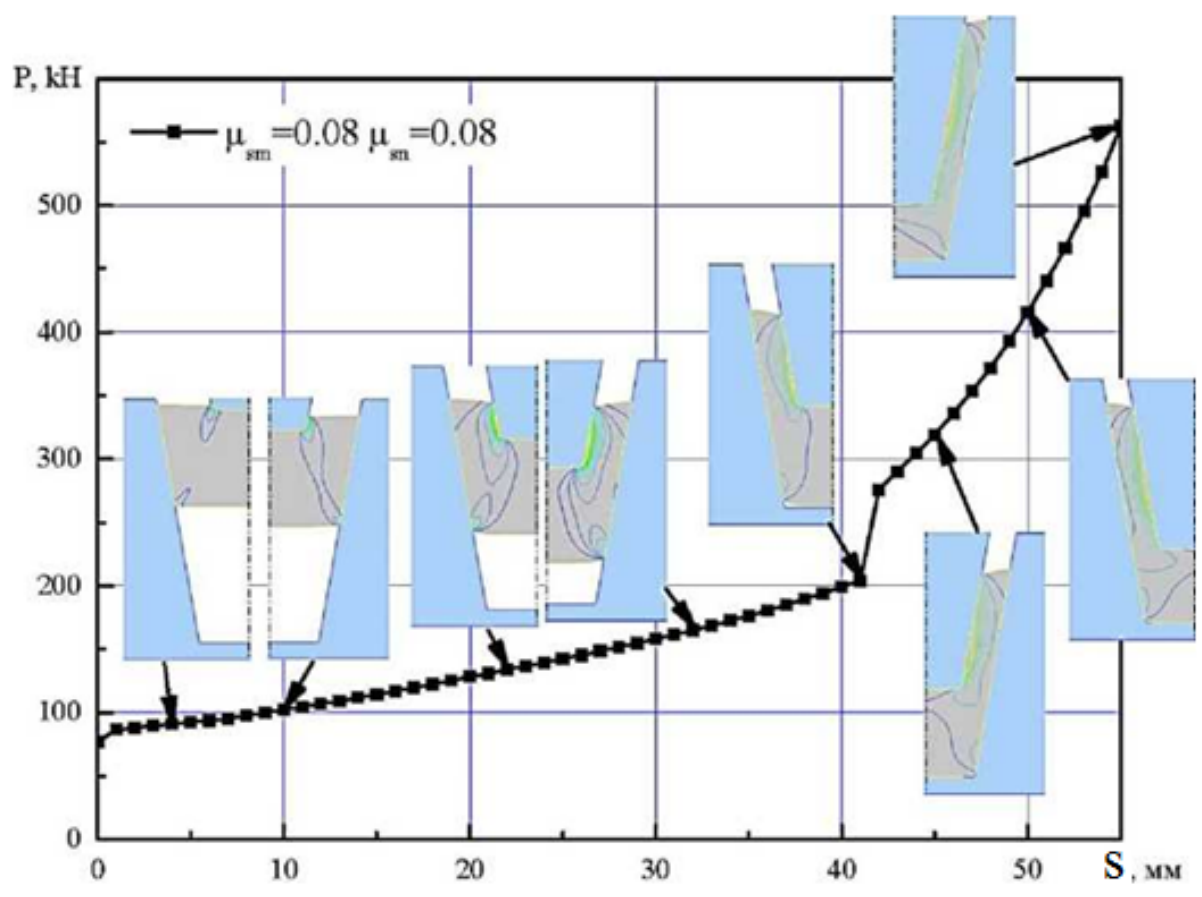

Рис. 2. Характер изменения силы выдавливания $P$ по ходу процесса $S$ 
В ходе исследований процесса комбинированного обратно-прямого выдавливания было установлено, что изменение силы выдавливания неравномерно и на диаграмме «Сила $P$-путь $S \gg$ можно выделить три стадии процесса выдавливания. На первой нестационарной стадии этапа (с ходом пуансона $S=30 \%$ от общей величины хода) происходит расспрессовка заготовки и интенсивный рост силы выдавливания. На второй стадии (с ходом до хода пуансона $S=65 \%$ процесс можно считать псевдо установившимся, т. к. увеличение силы выдавливания происходит плавно. Третья стадия процесса наступает, когда нижний торец полуфабриката соприкасается с торцом контрпуансона и характеризуется резким скачком силовых параметров за счет перехода от комбинированного течения к этапу обратного выдавливания.

Выявление коэффициентов трения, которые приведут к исключению конечной стадии обратного выдавливания при выбранной схеме проведения технологического процесса, производили путем их последовательного перебора с визуальной оценкой конечного формоизменения и анализом графика изменения силы выдавливания по ходу процесса.

Формирование очага пластической деформации (рис. 3) при значениях коэффициентов трения на матрице 0,36 и 0,08 на пуансоне в значительной мере аналогично очагу деформации для процесса внедрения, описанного в работах $[10,11]$.

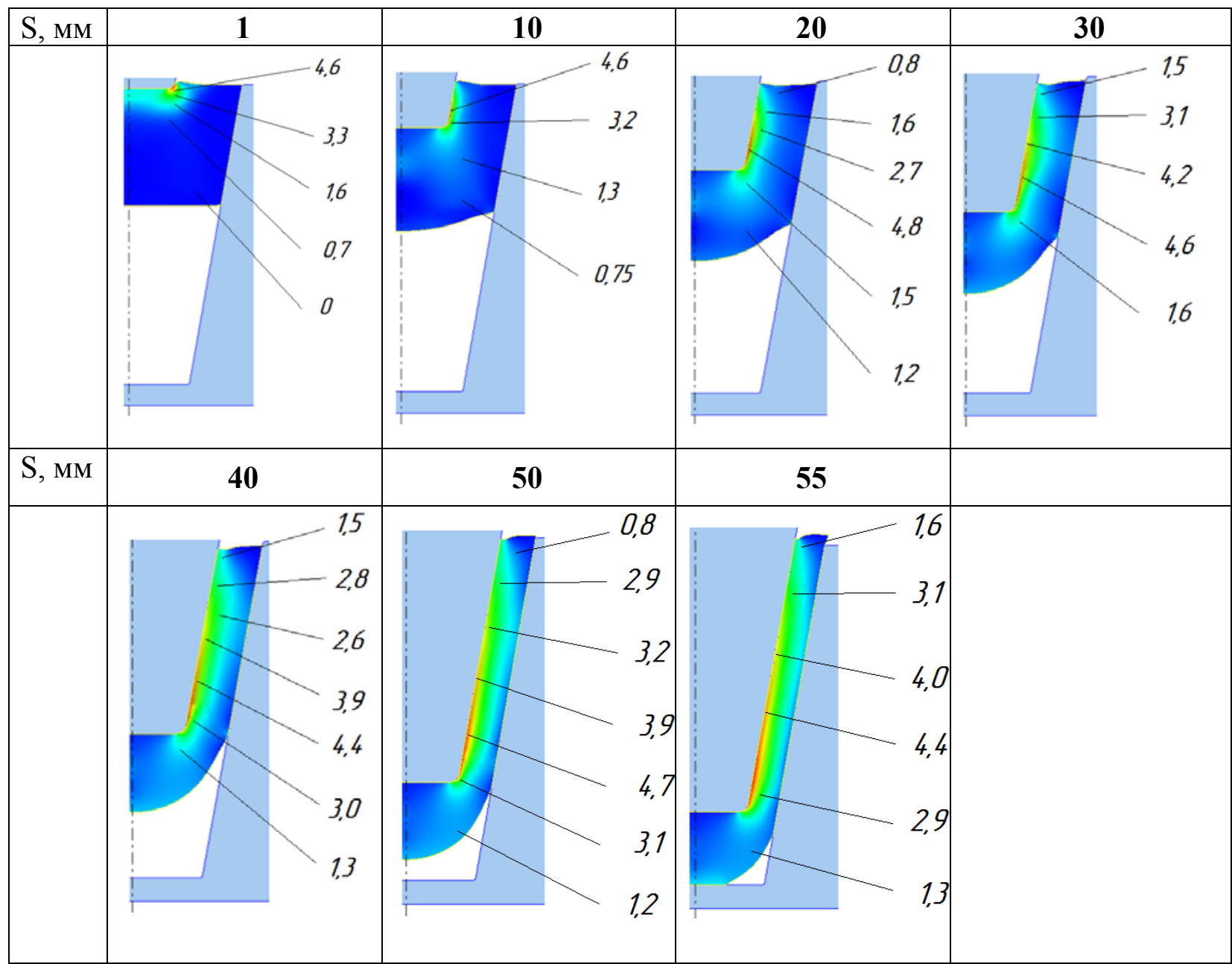

Рис. 3. Постадийное формоизменение заготовки в процессе обратно-прямого выдавливания и распределение интенсивности деформации по сечению конических деталей

В начальной стадии процесса $(S=10$ мм) зона интенсивной деформации примыкает к кромке пуансона и наиболее продеформированный слой металла распределяются вдоль боковой поверхности пуансона, где максимальное значение степени логарифмической деформации достигает 4,6, а минимальное 0,75 . На данном этапе доминирующими деформациями 
в объеме полуфабриката выступают деформации со степенью, равной 1,3 . На следующей стадии $(S=30$ мм) зона распределения интенсивности деформаций по-прежнему наблюдается вдоль боковой поверхности пуансона, и преобладающие деформации также имеют значение 1,3 . На конечной стадии $(S=55$ мм) неравномерный характер распределения степени деформации сохраняется и преобладающие деформации имеют величину 3,1 . Как и ожидалось, наиболее проработанной является стенка детали, а зона под торцом пуансона практически не деформирована. Можно отметить, что и дно конического стакана на стадии комбинированного выдавливания не подвергается деформации осадки, а стенка детали формируется за счет того объема металла, который расходуется из-за обжатия исходной заготовки по диаметру при ее проталкивании вниз в конической полости матрицы.

Анализ зависимости изменения силы выдавливания при обратно-прямом выдавливании в зависимости от условий контактного трения (рис. 4) показал, что даже при увеличении коэффициента трения на матрице до 0,36 наблюдается меньшее на 20-30 \% значение силы выдавливания, чем при коэффициенте трения на матрице 0,08 . Это объясняется отсутствием на конечной стадии собственно только обратного выдавливания.

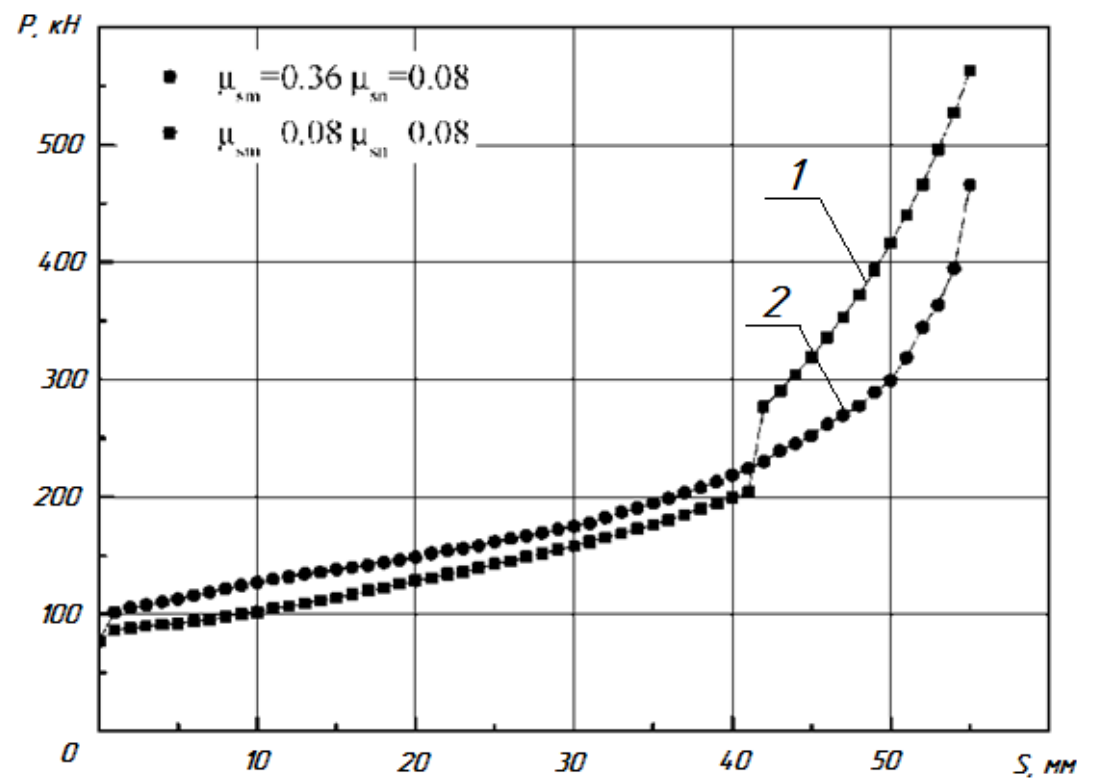

Рис. 4. График изменения силы выдавливания по ходу процесса деформирования в зависимости от влияния условий контактного трения на пуансоне и матрице:

$$
1-\mu_{s M}=\mu_{s n}=0,08,2-\mu_{s M}=0,36, \mu_{s n}=0,08
$$

Анализ формоизменения также показал, что протекание такого варианта процесса выдавливания, когда комбинированное течение металла сохраняется до завершения формообразования полой детали вполне возможно (рис. 5). В процессе деформирования видно, как при увеличении сил трения металла с матрицей наружная боковая поверхность полуфабриката залипает на стенке матрицы, в результате чего нижний торец детали принимает округлые формы и появляется дефект в виде незаполнения угла полости матрицы (рис. 5, а, б), При этом металл, необходимый для закрытия этого угла, переместился в стенку и в верхнюю часть детали, что способствует образования излишка на кромке детали и возможному появлению заусенца на этой кромке. Для устранения данного дефекта было принято решение уменьшить толщину заготовки с увеличением высоты ее расположения в полости матрицы, а толщину исходной заготовки принять равной толщине дна готовой детали (рис. 5, б). Поскольку длина образующей становилась больше, чем в первом варианте (рис. 5, а), то значения коэффициентов трения были приняты равными по 0,08 как для поверхности матрицы, так и для пуансона. Дефект в виде незаполнения угла матрицы остался (рис. 5, в, г), однако по размерам он оказался меньше, чем в первом варианте. 
При малых значениях коэффициентов трения на матрице и пуансоне течение металла происходит преимущественно в прямом направлении, и при этом возможно увеличение толщины дна в сравнении с толщиной исходной конической заготовки, размещенной в средней части полости матрицы. Увеличение длины наклонной образующей на матрице также влияет на течение металла. Чем меньше длина линии контакта заготовки с образующей матрицы, тем больше процессы выдавливания ставятся похожими на процесс штамповки, который характеризуется втягиванием заготовки в полость матрицы без уменьшения толщины дна заготовки. Во всех случаях более проработанной частью детали является стенка стакана с характерной неравномерностью деформации и максимумом степени обработки в слоях, прилегающих к пуансону (см. рис. 5, а, в).

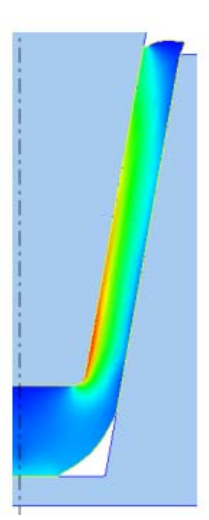

a

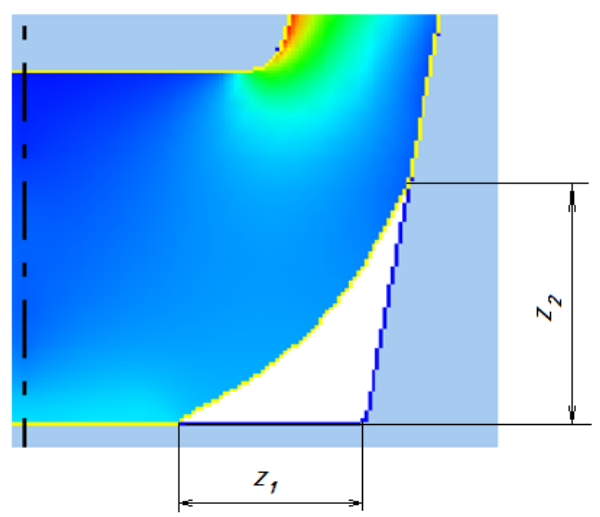

б

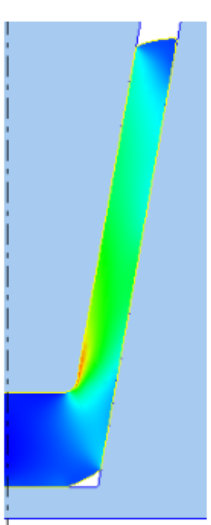

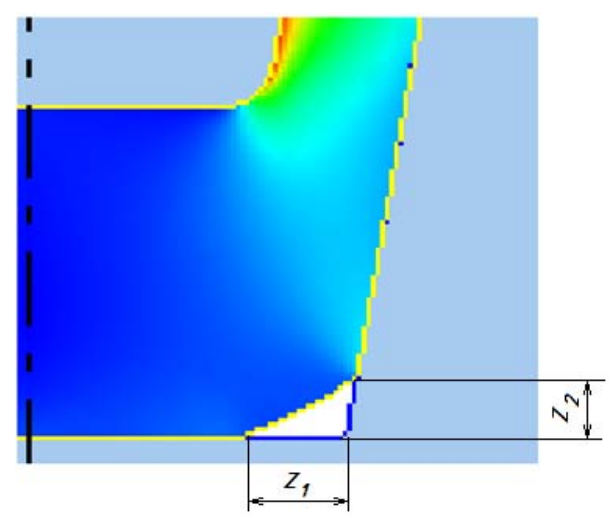

Рис. 5. Отклонение формы детали при комбинированном обратно-прямом выдавливании

Влияние на формоизменение заготовки условий контактного трения связано также с таким параметром, как отношение радиуса торца пуансона к радиусу дна полости матрицы. При значениях этого параметра в диапазоне от 0,4 до 0,8 увеличение значения коэффициента трения на пуансоне в большей степени влияет на уровень силовых характеристик процесса выдавливания, а при значениях, не входящих в данный диапазон, на особенности формоизменения заготовки. При значениях отношения радиусов менее 0,4 возможно появление у деталей дефектов в виде «прострелов» - поднутрений в донной части полости.

Увеличенные значения отношения радиусов (и степени деформации) более 0,8 способствуют более интенсивному течению металла из стенки стакана в прямом направлении.

Отношение радиуса пуансона к радиусу матрицы было увеличено до 0,9 (рис. 6), при этом угол наклона матрицы был равен углу наклона пуансона $\alpha=10^{\circ}$. Толщина заготовки была принята равной толщине дна готовой детали.

В исследуемом варианте, когда значения коэффициентов трения на матрице и пуансоне способствуют более интенсивному течению металла в прямом направлении, то есть минимальны, по ходу процесса выдавливания линия раздела течения металла смещается выше по стенке полуфабриката. Это приводит к появлению дефекта в виде зазора между донышком детали и рабочим торцом пуансона (см. рис. 6). Возможность появления такого рода дефекта при комбинированном выдавливании из-за опережающего выдавливания металла в прямом направлении отмечено ранее и другими исследователями [8]. Для количественной оценки условий образования этого дефекта необходимы более углубленные исследования, особенно с изменением условий трения в более широком диапазоне, характерном для изготовления деталей в горячем состоянии. 

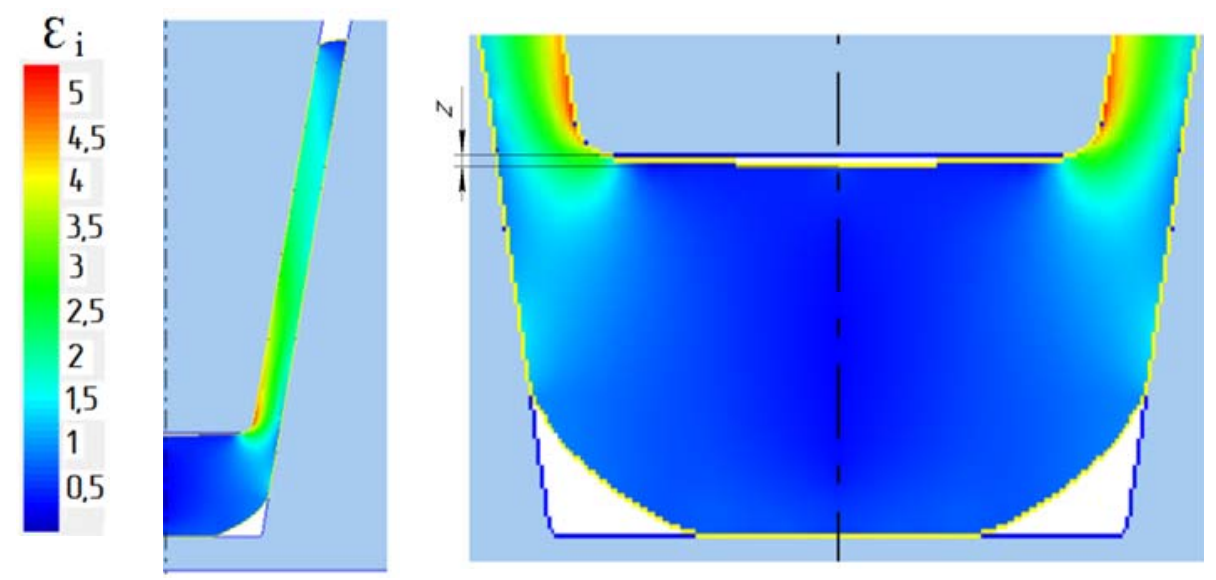

Рис. 6. Дефект в виде опережения металла и появления зазора перед торцом пуансона

Для изучения закономерностей поэтапного формообразования полой конической детали в зависимости от параметров процесса были проведены исследования комбинированного выдавливания в программном комплексе Deform-3D для схем с углами наклона образующих матрицы и пуансона $\alpha_{m}=\alpha_{p}$, равными $10^{\circ}, 15^{\circ}$ и $20^{\circ}$. Материал конической детали сплав АД31 сопротивлением деформации $\sigma_{s}=247 e^{0,136}$. Размеры исходной конической заготовки: диаметры 75 и 95 мм, толщина - 40 мм. Заготовки с конической формой обеспечивают лучшее центрирование и отсутствие перекосов при установке в матрице.

Формирование стенки стакана и дна детали происходит одновременно в течение всего процесса (рис. 6). Высота стенки увеличивается постепенно при различных образующих углах, однако после переходу к стадии обратного выдавливания при $\alpha_{m}=\alpha_{p}=10^{\circ}$ происходит резкое увеличение высоты стенки стакана.

При увеличении углов наклона образующих наблюдается уменьшение толщины донной части детали в течение всего процесса деформирования.
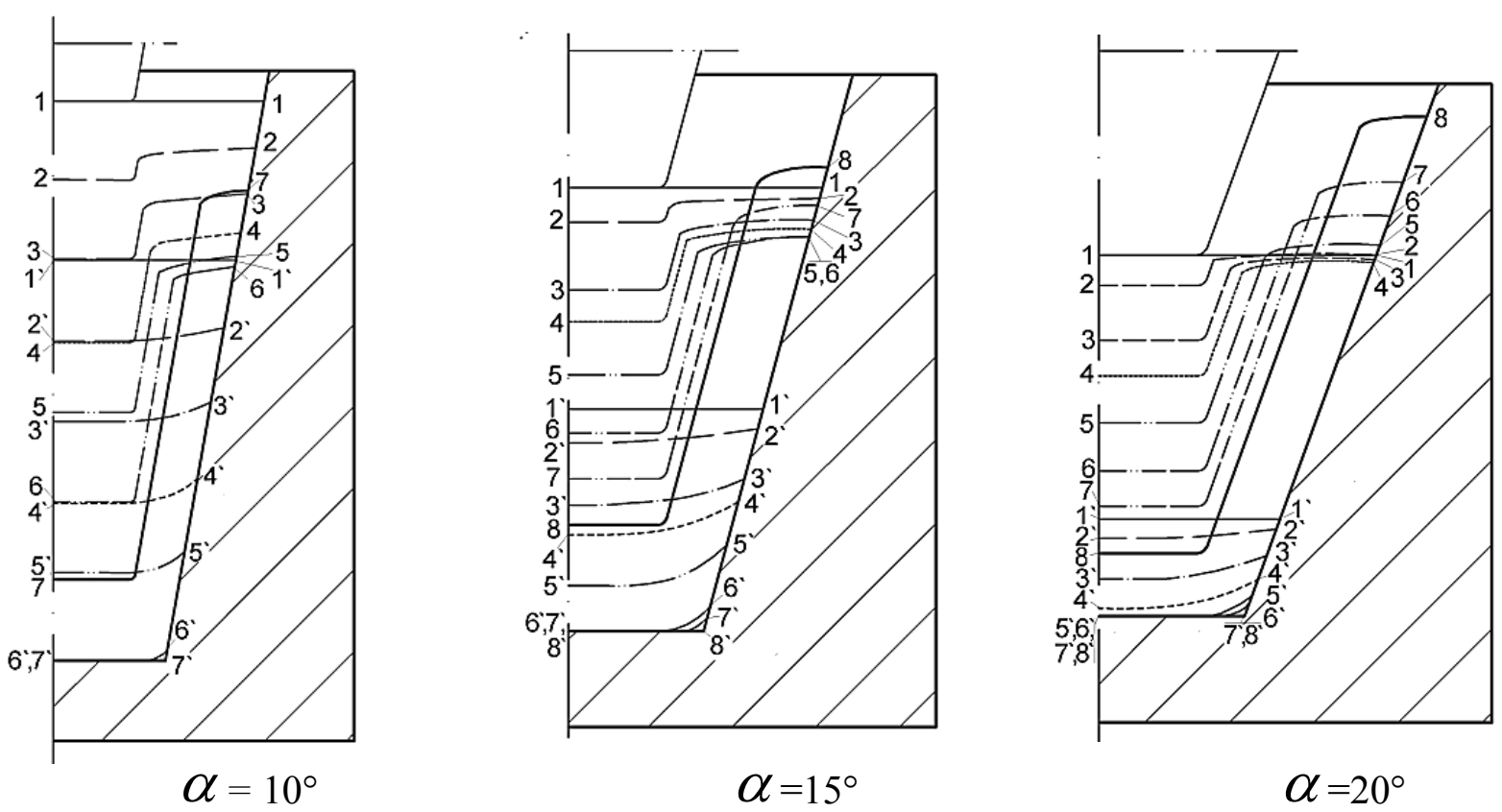

Рис. 6. Поэтапные контуры формируемой конической детали, полученные на основе МКЭ моделирования при различных углах наклона образующих инструментов $\alpha$ 
Для подтверждения результатов, полученных методом МКЭ, был проведен эксперимент по выдавливанию конических стаканов при углах инструментов, равных $10^{\circ}$. Заготовки были изготовлены из алюминиевого сплава АД31 в форме усеченного конуса с наметкой под пуансон.

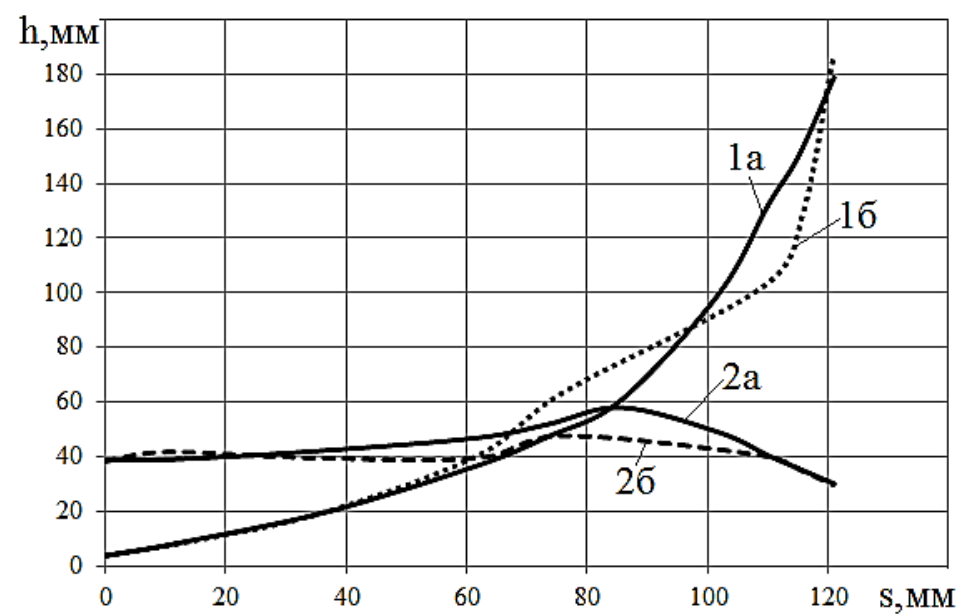

Рис. 2. График изменения высоты стенки стакана (1а - МКЭ, 16 - эксперимент) и толщины дна (2a - МКЭ, 26 - эксперимент) полой конической детали

По ходу процесса происходит втягивание металла в дно за счет заметно активного течения металла в прямом направлении. Это приводит к тому, что на промежуточной стадии происходит незначительное увеличение толщины дна формируемой детали. При контакте заготовки с торцом протипуансона и переходе к стадии обратного выдавливания наблюдается уменьшение толщины дна детали и резкое увеличение высоты стенки стакана.

В целом характер формоизменения заготовки, прогнозируемой моделью, подтверждается для исследованных условий контактного трения.

\section{ВЫВОДЫ}

В результате анализа процесса комбинированного обратно-прямого выдавливания конических стаканов установлено, что реализация процесса комбинированного обратнопрямого выдавливания возможна без конечной стадии обратного выдавливания. Реализация данного варианта протекания процесса наблюдалась при следующих технологических параметрах: коэффициент контактного трения по матрице 0,36 , по пуансону 0,08 ; углы наклона образующей матрицы и пуансона равны $10^{\circ}$.

Установлено, что при формообразовании полых конических деталей наблюдается образование дефектов в виде незаполнения углов полости и контура детали, а также в виде появления зазора между торцом пуансона и дном детали вследствие опережающего течения металла в прямом направлении из стенки полуфабриката.

Дальнейшие исследования процесса выдавливания конических деталей следует направить на получение обобщенных зависимостей для количественного описания параметров дефектов при влиянии основных параметров процесса.

\section{СПИСОК ИСПОЛЬЗОВАННОЙ ЛИТЕРАТУРЫ}

1. Романовский В.П. Справочник по холодной штамповке. 6-е изд., перераб. и доп. Ленинград: Машиностроение, 1979. 520 с.

2. Ковка и штамповка: Справочник: В 4 т. Т. 4. Листовая штамповка. Под ред. А. Д. Матвеева. Москва : Машиностроение, 1987. 544 с.

3. Алиев И. С., Кащенко Ю. А., Еремин В. П. Исследование технологического процесса выдавливания полых конических деталей. Прогрессивные технология, оборудование и оснастка для интенсификации проиессов обработки давлением : сб-к научн. трудов. Киев : УМК ВО, 1991. С. $22-31$.

4. Валиев С. А. Комбинированная глубокая вытяжка листовых заготовок. Москва : Машиностроение, 1973. $176 \mathrm{c}$. 
5. Алієв І. С., Калюжний В. Л. Визначення параметрів двохперехідного штампування високих конусних виробів з листової заготовки із пластичної міді. Вісник НТУ "ХПI". Сер. : Інновачійні технологї̈ та обладнання обробки матеріалів у махинобудуванні та металургії. 2016.30 (1202). С. 5-12.

6. Алиев И. С., Гнездилов П. В. Сравнительный анализ способов выдавливания полых конических деталей. XVII international scientific conference «New technologies and achievements in metallurgy, material engineering and production engineering» : Series: Monografie. 56. Częstochowa. 2016, pp. 179-182.

7. Александров А. А.,, Лексутов И. С. Моделирование процесса холодного поперечно-прямого выдавливания изделий с коническим дном. Омский научный вестник. 2007. 2 (56). С. 129-131.

8. Экк Е. В., Даммер А. Э., Кононов В. Т. Определение формоизменения и усилия комбинированного выдавливания полых поковок конической формы. Известия вузов. Черная металлургия. 1983. 2. С. 46-50.

9. Биба Н. В., Стебунов С. А., Гладков Ю. А., Мордвинцев П. С. QForm - универсальная и эффективна программа для моделирования коки и штамповки. Кузнечно-итамповочное производство. Обработка материалов давлением. 2011. 1. С. 36-42.

10. Алиев И. С., Корденко М. Ю., Самоглядов А. Д. Комбинированное выдавливание полых конических деталей. Обработка материалов давлением. Краматорск : ДГМА, 2018. 2 (47). С. 90-95.

11. Косенко М. В., Нагорская И. В., Гулькова О. В. Исследование начальной стадии выдавливания полых конических деталей. Обработка материалов давлением. Краматорск : ДГМА, 2009. 2 (21). С. 61-65.

\section{REFERENCES} (in Russian).

1. Romanovsky V.P. Handbook of cold stamping. Leningrad: Mechanical Engineering. 1979, 520 p.

2. Forging and stamping. Handbook. In 4 t., T. 4. Sheet stamping. Ed. Matveev A.D. Moscow: Mechanical Engineering. 1987, 544 p. (in Russian).

3. Aliiev I.S., Kashchenko Yu.A, Eremin V.II. The study of the technological process of extrusion of hollow conical parts. Progressive technology, equipment and accessories for the intensification of pressure working processes. Kyiv: UMK VO. 1991, pp. 22-31. (in Russian).

4. Valiev S.A. Combined deep drawing of sheet blanks. Moscow: Mechanical Engineering. 1973,176 p. (in Russian).

5. Aliiev I.S., Kalyuzhny V.L. Determination of parameters of two-transition high-cone stamping of sheet metal billet. Bulletin NTU "KhPI". Kharkiv. 2016, 30 (1202), pp. 5-12. (in Russian).

6. Aliiev I.S., Gnezdilov P.V. Comparative analysis of methods for extruding hollow conical parts. Proceedings of the 17th International Conference "New technologies and achievements in metallurgy, material engineering and production engineering”: Series: Monografie, 56, Częstochowa. 2016, pp. 179-182. (in Russian).

7. Alexandrov A.A., Leksutov I.S. Modeling the process of cold transverse direct extrusion of products with a conical bottom. Omsk Scientific Herald. 2007, 2 (56), pp.129-131. (in Russian).

8. Ekk E.V., Dammer A.E., Kononov V.T. Determination of the shape change and the efforts of combined extrusion of hollow forgings of a conical shape. Izvestiya. Ferrous Metallurgy. 1983, 2, pp. 46-50. (in Russian).

9. Biba N.V., Stebunov S.A., Gladkov Yu.A., Mordvintsev P.S. QForm, a universal and effective program for modeling forging and stamping. Forging and Stamping Production. Material Working by Pressure. 2011, 1, pp. 36-42. (in Russian).

10. Aliiev I. S., Kordenko M.Yu., Samoglyadov A.D. Combined extrusion of hollow conical parts. Material Working by Pressure. Kramatorsk: DSEA. 2018, 2 (47), pp. 90-95. (in Russian).

11. Kosenko M.V., Nagorskaya I.V., Gulkova O.V. Research of the initial stage of extrusion of hollow conical parts. Material Working by Pressure. Kramatorsk: DSEA. 2009, 2 (21), pp. 61-65. (in Russian).

Алиев И. С. $\quad$ - д-р техн. наук, проф., зав. каф. ОМД ДГМА;

E-mail: omd@dgma.donetsk.ua

Таган Л. В. $\quad$ - канд. техн. наук, ассистент кафедры ОМД ДГМА;

Самоглядов А. Д. - аспирант кафедры ОМД ДГМА;

Махмудов К. Д. $\quad$ - канд. техн. наук, проф. ДГТУ.

ДДМА - Донбасская государственная машиностроительная академия, г. Краматорск.

ДГТУ - Дагестанский государственный технический университет, г. Каспийск, РФ. 